\title{
DÜBLIN
}

Technological University Dublin

ARROW@TU Dublin

\section{Reliability Analysis of Footbridge Serviceability Considering Crowd Loading}

\author{
Joe Keogh \\ Technological University Dublin, jkeogh@ait.ie \\ Colin C. Caprani \\ Technological University Dublin, colin.caprani@tudublin.ie \\ Paul Archbold \\ Athlone Institute of Technology, parchbold@ait.ie
}

See next page for additional authors

Follow this and additional works at: https://arrow.tudublin.ie/engschcivcon

Part of the Structural Engineering Commons

\section{Recommended Citation \\ Keogh, J., Caprani, C., Archbold, P., Fannint, P.:Reliability Analysis of Footbridge Serviceability Considering Crowd Loading. IABMAS:6th International Conference on Bridge Maintenance, Safety and Management,Stresa, Lake Maggiore, Italy, on July 8-12, 2012.}

This Conference Paper is brought to you for free and open access by the School of Civil and Structural Engineering at ARROW@TU Dublin. It has been accepted for inclusion in Conference papers by an authorized administrator of ARROW@TU Dublin. For more information, please contact arrow.admin@tudublin.ie, aisling.coyne@tudublin.ie,gerard.connolly@tudublin.ie. Funder: ABBEST Scholarship Programme




Authors

Joe Keogh, Colin C. Caprani, Paul Archbold, and Paul Fanning

This conference paper is available at ARROW@TU Dublin: https://arrow.tudublin.ie/engschcivcon/35 


\title{
Reliability analysis of footbridge serviceability considering crowd loading
}

\author{
J. Keogh \& C.C. Caprani \\ Department of Civil \& Structural Engineering, Dublin Institute of Technology, Ireland
}

P. Archbold

Structures \& Materials Research Group (STRAIT), Athlone Institute of Technology, Ireland

P. Fanning

School of Civil, Structural \& Environmental Engineering, University College Dublin, Ireland

\begin{abstract}
The characteristic vertical response of flexible footbridges subjected to single pedestrian and crowd loading is examined in this paper. Typically, bridge vibrations produced from a crowd of pedestrians are estimated by using an enhancement factor applied to the effect caused by a single pedestrian. In this paper a moving force model is used in Monte Carlo simulations of a non-homogeneous sample of single pedestrians and crowds to estimate characteristic vertical vibration levels. Also in this work, statistical distributions of the bridge parameters are considered, these include flexural rigidity, mass and rotational stiffness at the supports. It was previously proven by the authors that the statistical range of pedestrian parameters, most notably the pacing frequency, has a significant effect on the bridge deck vibration. In this paper, probability of failure is calculated for ranges of pedestrian and bridge input parameters and it is found that the addition of statistical ranges for bridge parameters has only a small effect on the vertical acceleration response of the bridge deck. It reduced the probability of serviceability failure for a bridge with a natural frequency of $1.96 \mathrm{~Hz}$ and $2.2 \mathrm{~Hz}$ subjected to the loading of a characteristic single pedestrian.
\end{abstract}

\section{INTRODUCTION}

\subsection{Background}

Footbridges are not only seen as serving a linking function but also as eye-catchers and transparent landmarks (Butz 2008). Recent developments in the design of structures and structural materials along with pressure on designers to deliver more aesthetically pleasing structures have led to longer and lighter footbridges. Increasingly, these (typically) low-frequency structures are experiencing serviceability problems.

Vibrations of a bridge's walking surface can be expected if its natural frequency is within the pedestrian pacing frequency range, due to the dynamic nature of pedestrian load application. If these vibrations are large enough they will lead to discomfort for pedestrians crossing the bridge, thus exceeding the serviceability limit state. Well known examples of footbridges that experienced this situation are, the Millennium Bridge, London (Dallard et al. 2001), the Pont du Solferino, Paris (Danbon \& Grillaud 2005) and the T-Bridge, Japan (Fujino et al. 1993). The response of pedestrians to these vibrations is complicated and it is often difficult to establish a comfort criteria that satisfies all (Ramsmussen \& Von Scholten 2010). In addition it seems that people are becoming more sensitive to vibrations and, therefore, are more likely to complain (Bachmann 2002). Zivanovic et al (2005) gives a summary of some of the available literature on acceptable acceleration levels and highlights the variation in same.

Despite the issue of excessive vibrations of footbridges being well documented in the past decade, great uncertainty still exists in the area. The current design guidelines (Eurocode 5 (EN 1995-2:2004); ISO 10137 (2007); Setra Guideline (2006); UK Annex to Eurocode 1 (BS EN 1991-2:2003); and HIVOSS (2008)) are based on a number of different assumptions. As discussed by Pavic (2011), as a result of these varying assumptions, the predicted acceleration response of the bridge deck due to the passage of a crowd can vary by as much as a factor of four. This discord is reflective of the complexity of the problem, and its stochastic nature.

Vibrations of the bridge are often magnified by the passage of a crowd across the structure. Typically, bridge vibrations produced from a crowd of pedestrians are estimated by using an enhancement factor applied to the effect caused by a single pedestrian. However the models used are commonly deterministic and moreover do not consider the interaction between the bridge and the pedestrian. The need for a probabilistic approach to pedestrian loading has been acknowledged for a long time (Matsumoto et al, 1978; Wheeler, 1982). Despite this, de- 
sign codes, such as BS 5400 (2006) and Eurocode 5 (2004), use deterministic load models to determine the vertical acceleration response to a single pedestrian. These models are commonly unable to accurately predict the response due to a single pedestrian and usually overestimate it significantly (Zivanovic, 2006). Archbold (2008) reported that a moving force model, such as that used in BS 5400 (2006) does not allow for the interaction between the pedestrian and the moving structure, thus its predictions may be conservative.

\subsection{Approach of this work}

In this work pedestrians and the bridge are modelled using statistical distributions of their respective input parameters. The bridge used in the model is chosen to be susceptible to excitation from typical pedestrian pacing rates. The beam is modelled as a simplysupported beam with some rotational stiffness allowed for at the supports. A time-varying harmonic force, proposed by Fanning et al (2005), is used to represent the pedestrian force imparted to the bridge. Input parameters for the model include pedestrian mass, step length and pacing frequency, bridge mass, flexural stiffness, damping ratio and rotational stiffness at the supports.

The aim of the work herein is to assess the effect of introducing statistical ranges of the bridge and pedestrian parameters on the reliability and probability of serviceability failure of bridges assessed using currently available design guideline.

\section{HUMAN RESPONSE TO BRIDGE VIBARATION}

\subsection{Overview of phenomenon}

Zivanovic et al (2005) give a thorough literature review of human perception of surface vibrations, consequently only a brief overview is given here. In the case of loading on pedestrian bridges, the pedestrian is both the source and the receiver. Therefore if the vibrations are intolerable, the pedestrian will stop walking and the vibrations will dampen out. This is a simple solution to bridge vibrations but an unacceptable one, as users may choose an alternative route in future, obviating the bridge function.

Standing and walking pedestrians are known to experience bridge vibrations differently, with standing pedestrians being more susceptible. Zivanovic et al (2005) reports on Leonard (1966) which rightfully stated that it was not economically justifiable to design a footbridge so that a standing person would not feel vibrations, as users of the bridge will most likely be walking. It is acknowledged by Pedersen \& Frier (2010) that individual humans perceive vibrations differently and that the acceptance level of vibrations is thus a random variable in itself. As a re- sult, human perception of vibrations is difficult to predict due to the many variables: each person reacts differently to the same vibrations, and even an individual exposed to the same vibrations on different days is likely to react differently. The current vibration acceptability guidelines generally do not consider such variables.

\subsection{Serviceability limits}

Eurocode 5 (2004) is a recent design code for the design of timber structures and includes recommendations for vibration of footbridges. However, the response model defined is not material dependent, and so can be used to check the vibration serviceability of a footbridge constructed of any material (Pavic 2011). The code specifies use of the comfort criteria of EN1990:2002/A1 which states that if the natural frequency of a bridge is below $5 \mathrm{~Hz}$ it should be assessed for vibrations due to pedestrian loading. Using Eurocode 5 (2004) for a bridge with a natural frequency less than or equal to $2.5 \mathrm{~Hz}$, the bridge deck acceleration for a single pedestrian is:

$a_{1}=\frac{200}{M \zeta}$

where $M=$ bridge mass $(\mathrm{kg})$; and $\zeta=$ damping ratio of the bridge. The pedestrian is assumed to be walking at the same frequency as the bridge and so only the mass of the bridge and the damping value are used in the equation.

The acceleration serviceability limit defined in EN1990:2002/A1 is $0.7 \mathrm{~m} / \mathrm{s}^{2}$ in the vertical direction. Use of this equation, means that regardless of the natural frequency of the bridge, once it is below $2.5 \mathrm{~Hz}$, the single pedestrian response is the same. This equation neglects the sensitivity of vibrations of the deck to the pacing frequency found by Keogh et al (2010) and Pedersen and Frier (2010).

It is a common assumption in design codes that to obtain a single pedestrian response, a designer is to assume the pedestrian is walking at the same frequency of the bridge. From this single pedestrian acceleration response the response of the crowd is obtained. As a result if the prediction of the single pedestrian is overly conservative that this will be magnified for the crowd response.

BS $5400(1978,2006)$ used a deterministic moving force model for the acceleration due to a single pedestrian, assuming constant pedestrian mass, pacing frequency equal to bridge frequency and velocity equal to 0.9 times the pacing frequency where 0.9 is the step length in metres. This code gives an acceleration limit, $a_{\max }$, which varied with the change in bridge frequency and is given in Equation 2:

$a_{\max }=0.5 \sqrt{f_{0}}$ 
where $f_{0}$ is the natural frequency of the bridge. The variation in the acceleration limits between two codes is shown in Figure 1.

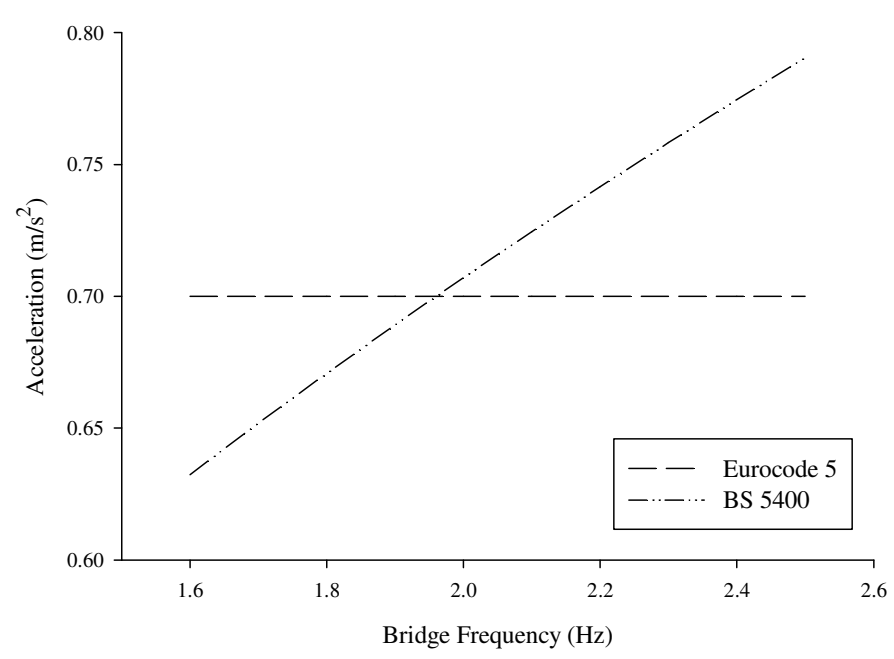

Figure 1. Serviceability Limit comparison - BS 5400 (2006) v's EN1990:2002/A1

It can be seen that both codes give a similar result at $2 \mathrm{~Hz}$ but above and below this value there is a difference that may be important for sensitive bridges. Zivanovic et al (2005) highlighted further variations in acceptable vibration levels in design codes of up to $25 \%$ at $2 \mathrm{~Hz}$, repeated here as Figure 2.

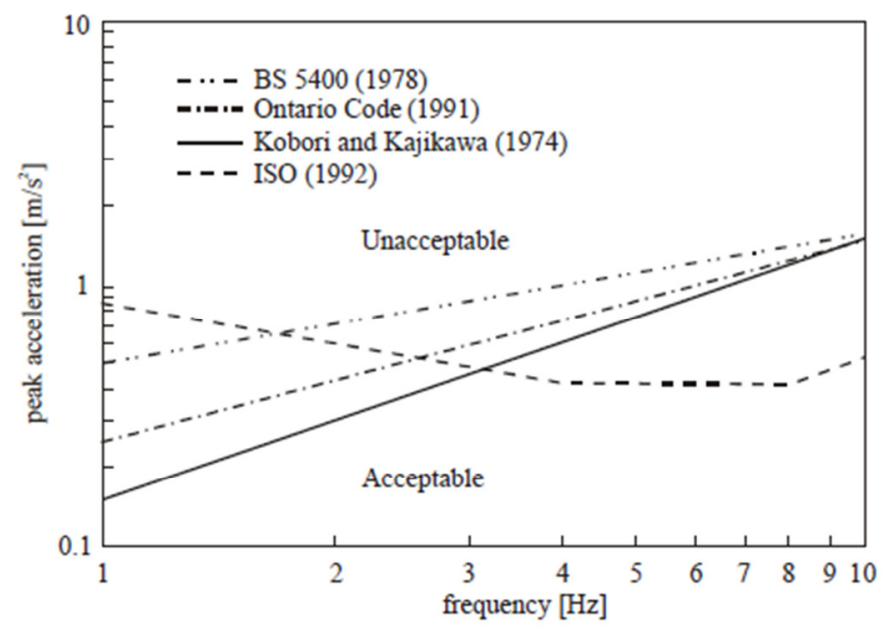

Figure 2. Acceptability of vertical vibrations in footbridges (after Zivanovic et al. 2005)

\section{NUMERICAL MODELLING}

\subsection{Overview}

The work presented here is based on a moving force model for single pedestrians as described by Caprani et al (2011). It is acknowledged that this model may be conservative since it does not consider mass or stiffness interaction between the pedestrian and moving bridge surface (Archbold 2008; Zivanovic et al. 2005).

\subsection{Bridge parameters}

This study focuses on three bridges which are in the typical range of pedestrian pacing frequencies. The bridges have a design or nominal fundamental frequency in vertical bending of $1.8 \mathrm{~Hz}, 1.96 \mathrm{~Hz}$ and $2.2 \mathrm{~Hz}$. These frequencies are calculated using the following general equation:

$\omega=\left(\frac{\lambda}{l}\right)^{2} \sqrt{\frac{E I}{m}}$

where $l=$ bridge length $(\mathrm{m}) ; E I=$ flexural stiffness of the beam; $m=$ bridge mass $(\mathrm{kg} / \mathrm{m})$; and $\lambda$ is the first root of the frequency equation, which for a simply supported beam is $\pi$. The mean bridge parameters displayed in Table 1 are used to determine the above nominal frequencies.

The damping ratio used in this work is selected following a review of available literature, most notably Pedersen and Frier (2010), Pavic (2011), and Bachmann et al (1995). It is given a coefficient of variation of $10 \%$. The variation of the modulus of elasticity used is that suggested by Omishore \& Kala (2009).

Table 1. Stochastic Bridge Parameters

\begin{tabular}{lccc}
\hline Bridge Parameter & Mean & SD* & CoV** \\
\hline Length; $l(\mathrm{~m})$ & 50 & -- & -- \\
Beam Width; $b(\mathrm{~m})$ & 2.0 & -- & -- \\
Beam Depth; $d(\mathrm{~m})$ & $* * *$ & -- & -- \\
& $\frac{b d^{3}}{12}$ & $0.1 I$ & 0.100 \\
Second Moment of Area; $I\left(\mathrm{~m}^{4}\right)$ & 500 & 50 & 0.100 \\
Beam Mass; $m(\mathrm{~kg} / \mathrm{m})$ & 0.5 & 0.05 & 0.100 \\
Damping Ratio; $\xi(\%)$ & 210 & 10 & 0.048 \\
Modulus of Elasticity; $E(\mathrm{GPa})$ & & &
\end{tabular}

* Standard Deviation.

** Coefficient of Variation.

$* * * \mathrm{~d}=0.490 \mathrm{~m}, 0.518 \mathrm{~m}, 0.560 \mathrm{~m}$ for $1.8 \mathrm{~Hz}, 1.96 \mathrm{~Hz}$ and 2.2

$\mathrm{Hz}$ bridges respectively.

\subsection{Bridge supports}

Rotational spring stiffness at the supports is accounted for in this work (Figure 3). This is done to reflect the reality of construction forms, in which the assumption of perfectly free rotation is not realized in practice. The rotational spring stiffness allowance will make the bridge slightly stiffer, increasing its natural frequency by a small amount. In addition, bridge fittings such as railings may increase the frequency of the bridge.

In the case of a simply supported beam with rotational spring supports, $\lambda$ of Equation 3 must satisfy the following frequency equation of Karnovsky \& Lebed (2004): 


$$
\begin{aligned}
&\left(k_{1}^{*}\right)^{2}+k_{1}^{*} \frac{\lambda(1+\alpha)(\sin \lambda \cosh \lambda)}{\alpha(1-\cos \lambda \cosh \lambda)} \\
&+\frac{2 \lambda^{2} \sin \lambda \sinh \lambda}{\alpha(1-\cos \lambda \cosh \lambda)}=0
\end{aligned}
$$

where $k_{1}^{*}$ and $k_{2}^{*}$ are dimensionless parameters given as follows:

$$
\begin{aligned}
& k_{1}^{*}=\frac{k_{1} l}{E I} \\
& k_{2}^{*}=\frac{k_{2} l}{E I}
\end{aligned}
$$

and the parameter $\alpha$ is given as:

$$
\alpha=\frac{k_{2}^{*}}{k_{1}^{*}}
$$

and $k_{1}$ and $k_{2}=$ rotational spring stiffness $(\mathrm{kNm} / \mathrm{rad})$.

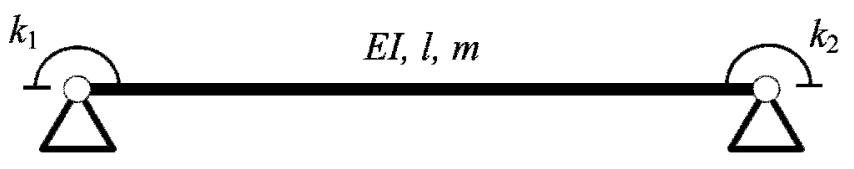

Figure 3. Considered beam with rotational spring supports.

\subsection{Pedestrian parameters}

In this work the sample of pedestrians is considered to be non-homogeneous and so their individual parameters follow statistical distributions. The pedestrian mass was represented by a log normal distribution with a mean of $73.9 \mathrm{~kg}$ and a coefficient of variation of $21.2 \%$ (Portier et al. 2007). The pedestrian stride length was taken to be normally distributed with a mean of $0.66 \mathrm{~m}$ (Barela \& Duarte 2008), and a coefficient of variation of $10 \%$ was assumed. The pacing frequency is also considered to be normally distributed with a calculated mean of $1.96 \mathrm{~Hz}$ with a standard deviation of $0.209 \mathrm{~Hz}$ following a literature survey (Pachi and Ji 2005; Ebrahimpour et al. 1996; Grundmann and Schneider 1990; Karmer and Kebe 1980; Matsumoto et al. 1978).

\subsection{Single pedestrian force model}

While walking, the vertical force induced by both feet is assumed to be of the same magnitude and to be periodic (Fanning et al. 2005; Zivanovic et al. 2005). During walking, since one foot is always in contact with the walking surface, the ground reaction forces (GRF) produced by consecutive footfalls overlap in time. This GRF can be represented as a Fourier series (Bachmann \& Ammann 1987; Rainer et al, 1988). However, in this work, each pedestrian is described by a moving force with just the first harmonic of the Fourier series (Archbold 2004) and is thus given by the following:

$$
P(t)=m_{P} g\left[1+r \sin \left(2 \pi f_{p} t\right)\right]
$$

where $m_{P}=$ pedestrian mass $(\mathrm{kg}) ; g=$ acceleration due to gravity $\left(\mathrm{m} / \mathrm{s}^{2}\right) ; f_{p}=$ pacing frequency $(\mathrm{Hz})$; and $r=$ dynamic force component from Fanning et al (2003), given by:

$r=0.25 f_{p}-0.1$

Further details on the numerical formulation of this moving force model are given in Caprani et al (2011).

\subsection{Crowd model}

A crowd length of $100 \mathrm{~m}$ and a width of $2 \mathrm{~m}$ is used to establish a representative crowd on the bridge at any point in time. The phase angle of the pedestrians is uniformly distributed in the interval 0 to $2 \pi$. A crowd density of $0.5 \mathrm{p} / \mathrm{m}^{2}$ was described by Pavic (2011) as being a 'busy' but not 'crowded' footbridge and so is the density used here. Pedestrian starting locations are based on a Poisson arrival process and are thus described by the exponential distribution.

The proportion of pedestrians taken to be synchronized; that is walking in-step, is termed the level of synchronization and is considered to range from 0 to $25 \%$ in this work. The pedestrians deemed to be synchronized are given the same pacing frequency and phase angle. These parameters are randomly selected according to their respective distributions previously given. The synchronized pedestrians are randomly distributed throughout the crowd.

\subsection{Vibration Response}

The response of interest is assessed using the 5second root-mean-square (RMS) from the acceleration history of each simulation (Archbold 2008; Pedersen \& Frier 2010). The maximum of the RMS for any one particular scenario is taken as the response of the bridge to that particular load case (da Silva et al. 2007). The serviceability limit used in this work is that given in Equation 2, which varies for each bridge generated.

\section{RELIABILITY ASSESSMENT}

\subsection{Basis}

To determine the acceleration response of the bridge to single pedestrian excitation, 10,000 simulations of random pedestrian and bridge loading events were performed and the maximum 5-second RMS vertical mid-span acceleration noted for each. In these simu- 
lations the bridge and pedestrian parameters varied as discussed in Section 3.

\subsection{Probability of failure}

The simulation results were analyzed and the probability of serviceability failure determined using a simple relative frequency measure:

$$
p_{f}=\frac{N_{f}}{N}
$$

where $N_{f}=$ number of simulations exceeding the serviceability limit as defined below, and; $N=$ total number of simulations.

As incorporating the statistical ranges of bridge parameters leads to variations in the natural frequency of the bridge, the bridge deck acceleration limit is determined using two limit state functions. Limit state function 1 (LSF1) uses the mean (design) values of the bridge parameters, and so represents the likelihood that the designed bridge will fail:

$$
g_{1}=0.5 \sqrt{\bar{f}}-a_{\mathrm{RMS}}
$$

Where $\bar{f}=1.96 \mathrm{~Hz}$ is the design bridge natural frequency and $a_{\text {RMS }}$ is the maximum $5 \mathrm{~s}$ RMS acceleration recorded during each simulation. If $\mathrm{g}_{1} \leq 0$ then the bridge has failed the serviceability limit state. Using Equation 2, the serviceability acceleration limit for the $1.96 \mathrm{~Hz}$ bridge is equal to $0.7 \mathrm{~m} / \mathrm{s}^{2}$.

Since the as-built bridge has a different natural frequency, or realization of parameter values, it will have a different serviceability limit for each realization. Thus a second limit state function is defined (LSF2) as:

$$
g_{2}=0.5 \sqrt{f}-a_{\mathrm{RMS}}
$$

where $f$ is the natural frequency of the bridge realized in each simulation. This limit state function reflects the possibility of modal testing being carried out after the bridge is commissioned into service to determine its actual natural frequency and thus its actual serviceability limit. For example, if the bridge frequency is realized to be $2.1 \mathrm{~Hz}$, the serviceability acceleration limit will be $0.725 \mathrm{~m} / \mathrm{s}^{2}$ from Equation 2. And so an acceleration of $0.71 \mathrm{~m} / \mathrm{s}^{2}$, for instance, would now be deemed acceptable.

\section{RESULTS}

\subsection{Rotational spring supports}

The rotational resistance used in this work is expressed as a fraction of the flexural rigidity of the beam, EI, and is taken to be uniformly distributed between 0.01 and 0.1 , where 0 represents absolutely no rotational stiffness (simply supported), and $\infty$ is a fully-fixed beam (see Equations 3 and 4). Figure 4 shows that the increase in the $\lambda$-value, used to calculate the frequency of the bridge, is almost linear with the increase in the dimensionless parameter related to the rotational stiffness at the supports.



Figure 4. Dimensionless parameter for rotational stiffness at beam supports

The effect of this rotational stiffness on the natural frequency of the bridge is evident in Table 2 where all other beam parameters are given the mean values. With the introduction of rotational stiffness at the supports, as may be expected, there is a slight increase in the natural frequency of the bridge, from $1.96 \mathrm{~Hz}$ to $1.979 \mathrm{~Hz}$.

Table 2. Effect of rotational stiffness on bridge frequency

\begin{tabular}{ccc}
$k_{1} *=k_{2} *$ & Eigenvalue $\left(\lambda_{1}\right)$ & Natural Frequency* $(\mathrm{Hz})$ \\
\hline 0.00 & $\pi$ or 3.141 & 1.960 \\
\hline 0.01 & 3.145 & 1.962 \\
0.02 & 3.148 & 1.964 \\
0.03 & 3.151 & 1.966 \\
0.04 & 3.154 & 1.968 \\
0.05 & 3.157 & 1.970 \\
0.06 & 3.162 & 1.973 \\
0.07 & 3.163 & 1.974 \\
0.08 & 3.166 & 1.975 \\
0.09 & 3.169 & 1.977 \\
0.10 & 3.173 & 1.979 \\
\hline
\end{tabular}

* All other bridge parameters are mean values

\subsection{Statistical distribution of bridge parameters}

It can be seen in Figure 5 that by using a statistical distribution of bridge parameters and including rotational stiffness, following 10,000 simulations, the outcome is a distribution of bridge natural frequencies. It was found that there was a change in the mean natural frequency, from the design $1.96 \mathrm{~Hz}$ to a mean, $\mu=1.975 \mathrm{~Hz}$ and a standard deviation, $\sigma=$ $0.112 \mathrm{~Hz}$. It has been previously reported by the authors in Keogh et al (2010) and by Pedersen \& Frier (2010) that bridge vibration response is greatest when the natural frequency and the pacing frequency 
coincide. As a result, an unexpected variation in natural frequency may change the acceleration response of a bridge significantly. It was reported by Keogh et al (2010) that if the bridge frequency is offset from the pacing frequency there is a reduction in the vibration response of the bridge deck.



Figure 5. Distribution of bridge natural frequencies incorporating with statistical range of parameters - design frequency = $1.96 \mathrm{~Hz}$; actual sample mean $=1.975 \mathrm{~Hz}$ and standard deviation $0.112 \mathrm{~Hz}$.

\subsection{Single Pedestrian Results}

\subsubsection{Single pedestrian probability of failure}

Assessment of the acceleration results following simulations of the passage of 10,000 random single pedestrians crossing the random bridge was carried out and the probability of serviceability failure of the bridge determined using the methods described in Section 4.2. This proved that there was very slight variation in the predictions of LSF 1 and LSF 2, with those predicted by LSF 2 being consistently less.



Figure 6. Probability of failure of the three bridges simulated with the mean values and the statistical distribution of bridge parameters.

\subsubsection{Single pedestrian response}

Using the present model, following 100,000 simulations of a stochastic single pedestrian crossing the $1.96 \mathrm{~Hz}$ bridge, the predictions of the acceleration response are $0.801 \mathrm{~m} / \mathrm{s}^{2}$ for the mean bridge parameters and $0.804 \mathrm{~m} / \mathrm{s}^{2}$ for random bridge parameters (including rotational stiffness). This shows that, in the case of a single pedestrian response, it is adequate to model a bridge using the mean bridge parameters. However, it is important to maintain the statistical range of pedestrian parameters, most notably, the pacing frequency as discussed by Keogh et al (2010) and Pedersen \& Frier (2010). Using Equation 1 meanwhile, which is taken from Eurocode 5, the acceleration due to a single pedestrian is found to be $1.6 \mathrm{~m} / \mathrm{s}^{2}$, which is more than double the allowable limits set out in both Eurocode 5 and BS5400 and also approximately twice the level determined from the method used herein. Eurocode 5 is considered by many, most recently Pavic (2011), to be overly conservative and reflects general deficiencies in the methods employed in design guides to estimate bridge response to dynamic pedestrian loading.

\subsection{Crowd Results}

\subsubsection{Crowd response}

The effects of the statistical distribution of bridge parameters on the acceleration response of a crowd with a density of $0.5 \mathrm{p} / \mathrm{m}^{2}$ (unrestricted pedestrian flow) and varying levels of synchronization (pedestrians walking in phase with each other) is considered. Again 10,000 simulations of random crowds crossing the bridge with a design frequency of 1.96 $\mathrm{Hz}$ were carried out and the vibration response assessed. The characteristic crowd response, is defined here as that response below which $95 \%$ of samples are expected to fall. It is common practice to take the 95\% response rather than the maximum response. (Pedersen and Frier 2010; Zivanovic et al. 2007).

It can be seen in Figure 7 that there is very little difference between the responses of the mean and random bridge parameters. The greatest difference is evident at $25 \%$ synchronization where there is a $7 \%$ difference in the results.

It is interesting to note that the crowd prediction using the Eurocode 5 (2004) is $18.4 \mathrm{~m} / \mathrm{s}^{2}$ which is greatly above the prediction of the model presented here (maximum acceleration of $\approx 8 \mathrm{~m} / \mathrm{s}$ with $25 \%$ synchronization). As discussed by Pavic (2011), the predictions of Eurocode 5 (2004) are far higher than other codes and guidelines used to predict acceleration responses due to crowd loading. To investigate this and the accuracy of the model presented here, the authors recreated the work carried out by Pavic (2011) and modelled the bridge used in that publications with constant parameters to compare the published results. 


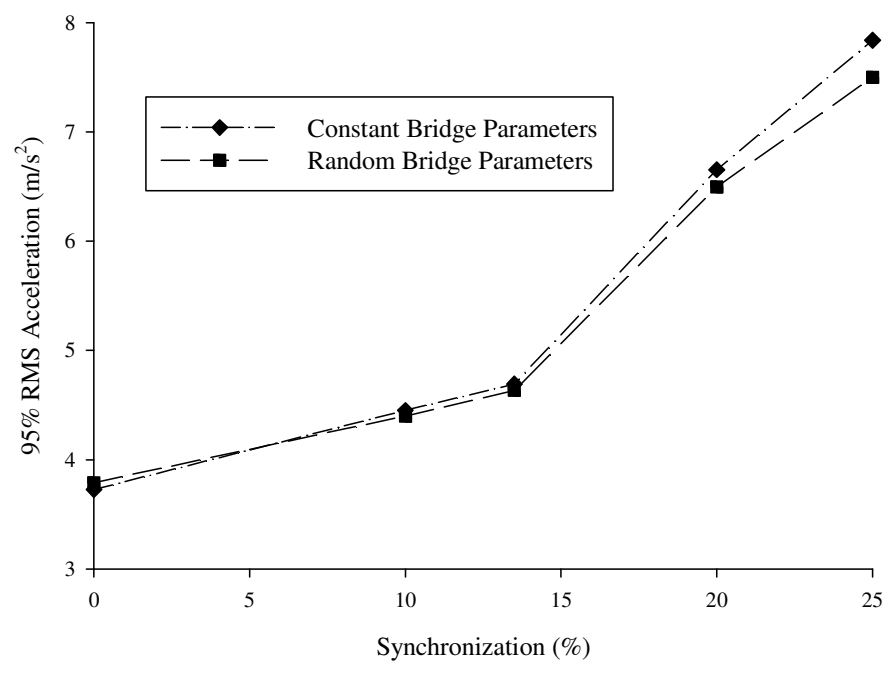

Figure 7. Crowd loading - constant bridge parameters v's random bridge parameters. Note: the random bridge parameters includes; mass, flexural rigidity, damping and rotational stiffness.

\subsubsection{Comparison to design codes}

The bridge used by Pavic (2011) was a $38.85 \mathrm{~m}$ bridge with a frequency of $2.17 \mathrm{~Hz}$ with a crowd density of $0.5 \mathrm{p} / \mathrm{m}^{2}$. Similar to the method employed by Setra guideline (2006) and the UK NA to Eurocode 1 , in this work the mass of the crowd are represented as a uniformly distributed load on the bridge, this has the effect of reducing the natural frequency of the bridge. It can be seen in Figure 8 that the characteristic 95\% RMS results from the model match very well with the predictions of the UK National Annex to Eurocode 1 for relatively low levels of synchronization. The results then diverge for levels of synchronization above approximately $10 \%$ This code is reported by Pavic to give the "most believable" results based on personal experience. It can be seen that the predictions of Eurocode 5 (2004) are a lot higher than any of the other codes or the work presented here

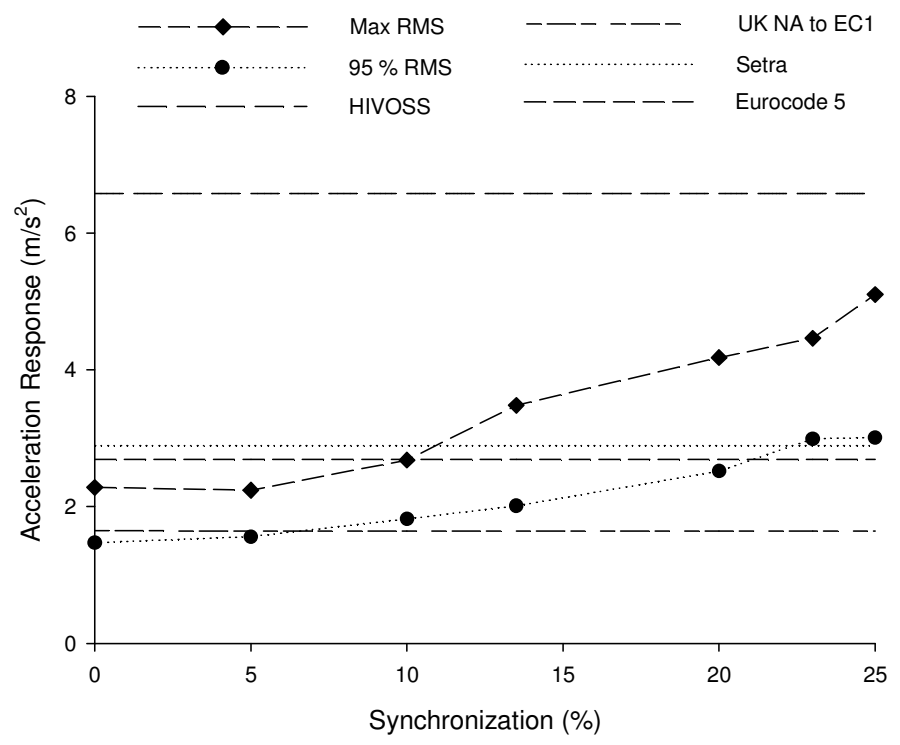

Figure 8. Comparison of model with design codes

\section{CONCLUSIONS}

\subsection{Conclusions}

Using a statistical range of parameters for the bridge parameters and introducing rotational stiffness at the supports, as expected increased the natural frequency of the bridge.

It has been shown in this work that introducing statistical ranges for the bridge parameters does affect the predictions of the single pedestrian and crowd bridge acceleration response. However, for the variances of the parameters considered here, the change is very small and so it can be concluded that for low-variance high-certainty construction, the mean parameters of the bridge can be used. However, it must be stressed that the incorporation of statistical ranges for pedestrian parameters, most notably pacing frequency, is of the upmost importance in obtaining accurate responses.

Moreover, it has been shown that there is relatively high disparity between current footbridge design guidelines, both in terms of allowable vibration limits and also in the methods used to predict vertical vibrations from pedestrians.

\section{ACKNOWLEGEMENTS}

The authors would like to acknowledge the Dublin Institute of Technology ABBEST Scholarship Programme for supporting this research.

\section{REFERENCES}

Archbold, P. 2008. Evaluation of novel interactive load models of crowd loading on footbridges, Proceedings of 4th Symposium on Bridge and Infrastructure Research in Ireland, National University of Ireland, Galway, 35-44.

Archbold, P. 2004. Novel Interactive Load Models for Pedestrian Footbridges, PhD Thesis, University College Dublin, 2004.

Bachmann, H., Amman, W., Dieschl, F., Eisenmann, J., Floegl, I., Hirsch, G., Klein, G., Lande, G., Mahrenhiltz, O., Natke, H., Nassbaumer, H., Pretlove, A., Rainer, J., Saemann, E. \& Steinbeisser, L. 1995. Vibration Problems in Structures Practical Guidelines. Birkhauser, Berlin.

Bachmann, H. 2002. Lively Footbridges - A Real Challenge, Proceedings of the International Conference on the Design and Design and Dynamic Behaviour of Footbridge. Paris, France, 20-22 November.

Bachmann, H. and Ammann, W. 1987. Vibrations in Structures-Induced By Man and Machines, IABSE, Structural Engineering Document 3, Zurich.

Barela, A.M.F. and Duarte, M. 2008. Biomechanical characteristics of elderly individuals Walking on land and on water', Journal of Electromyography and Kinesiology, 18(3), 446454.

BSI 2008. UK National Annex to Eurocode 1: Actions on Structures - Part 2: Traffic Loads on Bridges, NA to BS EN 1991-2-2003, British Standards Institution, London, UK. 
BSI 2006. Steel, Concrete and Composite Bridges, Part 2: Specification for Loads; Appendix B: Vibration Serviceability Requirements for a Foot and Cycle Track Bridges. BS5400, British Standards Institution, London, UK.

BSI (1978), Steel, Concrete and Composite Bridges, Part 2: Specification for Loads; Appendix C: Vibration Serviceability Requirements for a Foot and Cycle Track Bridges. BS5400, British Standards Institution, London, UK.

Butz, C. 2008. Codes of Practice for Lively Footbridges: State of the Art and Required Measures, Proceedings of the Third International Conference Footbridge 2008, Porto, 2-4 July.

Caprani, C.C., Keogh., J, Archbold, P. \& Fanning, P. 2011. Characteristic Vertical Response of a Footbridge Due to Crowd Loading, Proceedings of Eurodyn 2011, The $8^{\text {th }}$ International Conference on Structural Dynamics, Leuven, Belgium, 4-6 July.

Da Silva, J., da Vellasco, P., de Andrade, S. de Lima, L. \& Figueiredo, F. 2007. Vibration analysis of footbridges due to vertical human loads, Computers and Structure 85, 16931703.

Dallard, P., Fitzpatrick, A.J., Flint, A., Low, A., Ridsdill Smith, R.M., Willford, M. \& Roche, M. 2001. London Millennium Bridge: Pedestrian-Induced Lateral Vibration, ASCE Journal of bridge Engineering, 6(6), 412-417.

Danbon F. \& Grillaud, G. 2005. Dynamic Behaviour of a Steel Footbridge. Characterization and Modelling of the Dynamic Loading Induced by a Moving Crowd on the Solferino Footbridge in Paris, Proceedings of the Second International Conference Footbridge 2005, Venice, 6-8 December.

EN 2004. Eurocode: Basis of structural design, BS EN 19902002+A1:2005, European Committee of Standardization, Brussels.

EN 2004. Eurocode 5: Design of timber structures - Part 2: Bridges, EN 1995-2:2004, European Committee of Standardization, Brussels.

Ebrahimpour, A., Hamam, A., Sack, R.L. and Patten, W.N. 1996. Measuring and modeling dynamic loads imposed by moving crowds, ASCE Journal of Structural Engineering, 122(12), $1468-1474$.

Fanning, P., Archbold, P. \& Pavic, A. 2005. A Novel interactive Pedestrian load model for Flexible Footbridges, Proceeding of the 2005 Society for Experimental Mechanics Annual Conference on Experimental and Applied Mechanics, Portland, Oregon, 7-9 June.

Fanning, P., Archbold, P., Pavic, A. \& Reynolds, P. 2003. Transient Response Simulation of a Composite Footbridge to Crossing Pedestrians, Recent Developments in Bridge Engineering, K. Mahmoud, ED., Swets \& Zeitlinger Publishers, Lisse, The Netherlands. ISBN 9058096068.

Fujino, Y., Pacheco, B.M., Nakamura, S. \& Warnitchai, P. 1993. Synchronization of human walking observed during lateral vibration of a congested pedestrian bridge, Earthquake Engineering and Structural Dynamics, 22(9), 741758.

Grundmann, H and Schneider, M. 1990. Stochastic Representation of Footbridge Vibrations Taking into Account Feedback effects. In W.B. Kratzig et al. (Eds.), Proc. Eur. Conf. on Structural Dynamics, Eurodyn '90, Bochum, Balkema, Rotterdam.

HIVOSS 2008. Design of Footbridges Guideline: Human Induced Vibrations of Steel Structures, RFS2-CT-200700033. Available at: http://www.stb.rwth-aachen.de/projek te/2007/HIVOSS/download.php.

ISO 2007. Bases for Design of Structures - Serviceability of Buildings and Walkways against Vibrations, ISO 10137:2007, International Organization for Standardization.

Karnovsky, I.A. \& Lebed, O.I. 2004. Free Vibrations of Beam and Frames: Eigenvalues and Eigenfunctions, The McGraw-Hill Companies, Inc., New York.
Keogh, J., Archbold, P., Caprani, C. and Fanning, P. 2010. Estimating the Characteristic Vertical Response of a Flexible Footbridge due to Crowd Loading, Proceedings of the BCRI 2010 Conference, Cork, Ireland.

Kramer, H. and Kebe, H.W. 1980. Man-induced structural vibrations, Der Bauingenieur, 54(5), 195 - 199.

Leonard, D.R., 1966. Human tolerance levels of bridge vibrations, TRRL ReportNo. 34, Road Research Laboratory.

Matsumoto, Y., Nishioka, T., Shiojiri, H. \& Matsuzaki, K. 1978. Dynamic design of footbridges, IABSE Proceedings, 2, Paper P-17/78, Zurich.

Omishore, A. \& Kala, Z. 2009. Reliability analysis of steel structures with imperfections. Available at: http://www.nordicsteel2009.se/pdf/137.pdf

Pachi, A. and Ji, T. 2005. Frequency and velocity of people walking, The Structural Engineer, 83(3), 36-40.

Rainer, J., Pernica, G. \& Allen, D. 1988. Dynamic Loading and Response of Footbridges, Canadian Journal of Civil Engineering, 15 (1), 66-71.

Pavic, A. 2011. Vertical Crowd Dynamic Action on Footbridges: Review of Design Guidelines and Their Application, Proceedings of the Fourth International Conference Footbridge 2011, Wroclaw, 6-8 July.

Pendersen, L. \& Frier, C. 2010. Sensitivity og footbridge vibrations to stochastic walking parameters, Journal of Sound and Vibration, 329(13), 2683-2701.

Portier, K., Tolson, J.K., \& Roberts, S.M. 2007. Body weight distributions for risk assessment, Risk Analysis, 27(1), 1126.

Rasmussen, M.B. \& von Scholten, C. 2010. Arched Footbridge - exceptional design, Denmark, Structural Engineering International: International Association for Bridge and Structural Engineering, vol. 20, 206-214.

Setra 2006. Footbridges: Assessment of Vibration Behaviour of Footbridges Under Pedestrian Loading, Technical Guide, Service d'Etudes techniques des Routes et Autoroutes, Paris.

Wheeler, J. 1982. Prediction and control of pedestrian induced vibration in footbridges, Journal of Structural Division, 108(9), 2045-2065.

Zivanovic, S., Pavic, A. \& Reynolds, P. 2007. Probabilitybased estimation of footbridge vibration due to walking, Proceedings of the $25^{\text {th }}$ International Modal Analysis Conference, Orlando, Florida.

Zivanovic, S. 2006. Probability-Based Estimation of Vibration for Pedestrian Structures due to Walking, PhD Thesis, University of Sheffield, UK.

Zivanovic, S. Pavic, A. \& Reynolds, P. 2005. Vibration Serviceability of Footbridges Under Human-Induced Excitation: A Literature Review, Journal of Sound and Vibration, 279(1-2), 1-74. 